\title{
Addressing Mathematics Anxiety through Developing Resilience: Building on Self-Determination Theory
}

\author{
Sue Johnston-Wilder ${ }^{1}$, Clare Lee ${ }^{2}$, Kate Mackrell ${ }^{3}$ \\ ${ }^{1}$ University of Warwick (Education Studies), Coventry, UK \\ ${ }^{2}$ The Open University, Milton Keynes, UK \\ ${ }^{3}$ Independent Researcher, Brighton, UK \\ Email: sue.johnston-wilder@warwick.ac.uk, clare.lee@open.ac.uk
}

How to cite this paper: Johnston-Wilder, S., Lee, C., \& Mackrell, K. (2021). Addressing Mathematics Anxiety through Developing Resilience: Building on Self-Determination Theory. Creative Education, 12, 2098-2115.

https://doi.org/10.4236/ce.2021.129161

Received: August 26, 2021

Accepted: September 21, 2021

Published: September 24, 2021

Copyright $\odot 2021$ by author(s) and Scientific Research Publishing Inc. This work is licensed under the Creative Commons Attribution International License (CC BY 4.0).

http://creativecommons.org/licenses/by/4.0/

\begin{abstract}
Mathematics-specific anxiety is anxiety that impedes mathematical thinking and progress, and creates distress for many learners, or at the least a tendency to avoid mathematical thinking. Such anxiety is prevalent. The importance of mathematics to economic recovery is well-established; in order to meet the need for mathematics, the high levels of mathematics anxiety that stand in the way of individual mathematical progress should be addressed. Using a case study involving an adult learner, we use Self-Determination Theory to explain why mathematical resilience is a concept which can work against anxiety and for a positive stance towards mathematics. Work on mathematical resilience demonstrates that well-informed, subject-specific interventions can help people manage emotions, including anxiety, and improve progress and uptake in mathematics. We illustrate ways in which the focus of Self-Determination Theory on meeting basic psychological needs (autonomy, competence and relatedness), to enhance wellbeing and prevent harm, provides grounding for much good practice in mathematics education and specifically for work in mathematical resilience. The tools of mathematical resilience go beyond what is currently proposed in SDT research. We illustrate ways in which these tools can specifically facilitate learners' emotion regulation, which we propose is integral to mathematical learning competence, leading to greater mathematical wellbeing, learning, and release from mathematics anxiety.
\end{abstract}

\section{Keywords}

Mathematics Anxiety, Mathematical Resilience, Self-Determination Theory, Mathematical Learning Competence 


\section{Introduction}

The two months-long lockdowns in the UK due to the COVID-19 pandemic in 2020/21 resulted in all schools being closed to most pupils. Widnall et al. (2020) found that, during this time of COVID-related school closures, anxiety amongst some school-aged children was significantly reduced. The inevitable conclusion is that some aspects of schooling may actually be harmful for children's well-being.

As we, along with many others, consider the well-being of our young people of the highest priority, this report gives cause seriously to identify and tackle those aspects of school that are known to provoke anxiety, one of which is the environment in which mathematics is currently learned (Finlayson, 2014; Nardi \& Stewart, 2003). Ashcraft and Krause (2007) have shown clearly that many aspects of commonly accepted mathematical pedagogy, such as an over-regard for speedy recall and an under-regard for understanding concepts, give rise to mathematical anxiety and avoidance which have debilitating consequences for learners in terms of their potential careers and economic activity (Johnston-Wilder et al., 2014).

Mathematics-specific anxiety also has wider consequences: the world faces huge challenges that involve mathematical thinking, including climate change and economic injustice, but there is widespread underachievement in mathematics and mathematics-related subjects which may be attributable to mathematics anxiety and avoidance (OECD, 2013). This underachievement affects the supply of Science Technology Engineering and Mathematical (STEM) graduates adversely at a time when those with STEM expertise are much needed (Correia et al., 2010; EMSI, 2018). Recent UK government initiatives to improve mathematics education and increase the supply of people with mathematics qualifications (Gov.uk, n.d.) have not acknowledged how anxiety might interfere with that process (Ellis et al., 2016) or how mathematics anxiety and lack of confidence might be addressed. We believe that governments will continue to waste precious resources and continue to make the problem worse without substantial attention to how the prevalent development of mathematics anxiety in mathematics classrooms can be mitigated.

In this paper, we propose addressing mathematics anxiety through developing mathematical resilience within the framework of Self-Determination Theory (SDT) (Ryan \& Deci, 2018). We define mathematical resilience as "maintaining self-efficacy in the face of personal or social threat to mathematical well-being" (Johnston-Wilder \& Lee, 2019). SDT is premised on the importance of meeting basic psychological needs to promote wellbeing, ensure psychological safety, and avoid psychological harm (Deci \& Ryan, 2000; Ryan \& Deci, 2018). SDT provides important justification for most premises of the work on mathematical resilience; in this paper, we illustrate with a case study how SDT explains mathematics anxiety as resulting from frustration of basic psychological needs. However, SDT does not in itself provide tools for action; here we show how the tools of mathematical resilience can be used to meet the basic psychological needs currently 
being thwarted within many mathematics classrooms and thus improve learners' mathematics-specific well-being and thereby their willingness to engage in mathematics and develop competence in learning mathematics.

\section{Introducing Jackie}

Research in mathematics classrooms supports the conclusion that basic needs as set out in Self-Determination Theory (SDT) (Ryan \& Deci, 2018) are routinely thwarted and that ill-being results, particularly mathematics-specific anxiety (Durmaz \& Akkus, 2016). To illustrate the harm that results from thwarting basic needs in mathematics and how that may happen, this paper draws upon data from one author, Sue, working with case study participant, "Jackie". Jackie's case also shows how historical harm can be addressed and the benefits that can accrue from doing so.

Jackie is a middle-aged tutor of UK engineering apprentices. She contacted Sue as she wished to address her own "anxiety and avoidance, even hatred, towards mathematics" and had become aware of the work that Sue had been doing with her colleagues. Sue offered her as many one-to-one sessions as she needed at a mutually agreed venue. In these sessions, they would talk through her feelings towards mathematics and work on some straightforward mathematics together. When asked if her data could be used in a publication, she readily gave informed consent.

\section{Key Ideas from SDT Related to Learning Mathematics}

SDT sees people as having both agency and a natural tendency towards growth. The satisfaction of basic psychological needs gives rise to observable and meaningful positive consequences for learners' wellbeing and an opportunity to thrive. The frustration or deprivation of these needs gives rise to significant harm (Ryan \& Deci, 2018), including the development of anxiety. There are three key basic psychological needs, according to Ryan and Deci (2018):

Autonomy is the need to regulate actions in accordance with authentic interests and values. A person acting with autonomy (or with autonomous motivation) feels their actions are volitional, congruent, and integrated; a person acting out of "controlled regulation" experiences being controlled by external or internal pressure. An important aspect of autonomy is the ability to choose actions to meet the other two basic needs.

Competence is the need to feel effective in interactions within important life contexts, and having the means to exercise, expand, and express capacities. When individuals are prevented from developing skills or understanding, their need for competence remains unmet; consequently, they are likely to experience feelings of failure and inadequacy.

Relatedness is the need to feel valued, connected, and have a sense of belonging, experiencing others, and being experienced, as responsive, sensitive and caring. If the need for relatedness is not met, individuals can experience loneli- 
ness and abandonment, feel they do not fit in and, in a learning context, feel "stupid" in relation to others.

In Jackie's case, the environment in which she was required to learn mathematics thwarted these basic needs in several ways and she saw the result as having a negative impact on her life choices. Here we explain how her needs were thwarted:

Autonomy thwarting. An example of an autonomy-thwarting learning environment (Niemec \& Ryan, 2009) is the UK system of setting children commonly used in many schools. Setting is placing pupils in groups according to some perceive notion of ability. Learners are often not given any input into setting discussions or choice as to which set they join. This happened to Jackie, who reports being "demoted" to a group that was studying commercial mathematics for O-level: "there wasn't a discussion about it, I was just moved across". Further aspects of mathematics learning environments that led to Jackie feeling her autonomy was thwarted are the use of examinations results as gate keepers and the lack of meaning or purpose attributed by teachers to the processes learned in mathematics.

Gate keeping. Students are required to achieve a prescribed grade in mathematics for entry into many courses and careers, including teaching and engineering. If circumstances prevent the achievement of that grade, then the route to that career appears closed. Working with engineering apprentices, Jackie recognised she might have found engineering an interesting choice of career; her poor examination results and disaffection with mathematics meant that she did not consider such a career possible when she left school.

Lack of meaning. Lack of meaning for Jackie was about not being able to make sense of something unless she understood its purpose; in common with many adults, she did not understand the purpose of " $x$ " until after the sessions with Sue. Jackie said:

I remember seeing x's on the board and it meant nothing. It meant nothing. I couldn't relate to an $x$ for the life of me and I thought, well, whatever you do with that $\mathrm{x}$ it doesn't matter because I still don't know what $\mathrm{x}$ is. ... And that's what was completely missing for me, really, because I think, yeah, if someone had sat me down and said, so maths is the language of engineering, and then went on to say what is engineering and why does that matter, or how do we build buildings, how do we create factories, all those things, I'd have seen that bigger picture and thought, ok. I see now why that's important.

Jackie's account is wholly from her own perspective; she reports with the addition of hindsight. Nevertheless, her story of feeling that algebra is presented as particularly meaningless is shared by many (see for example, Nardi \& Steward, 2003).

Competence thwarting. There is a prevalent message in society that some people are not good at mathematics, and never will be; that is, they are unable to devel- 
op feelings of competence in mathematics, therefore it would be a waste of time to try. This idea seems to be why setting is widely accepted and even advocated. Setting is an integral part of Jackie's description of the experiences that led to her mathematical anxiety and avoidance:

I was identified as being particularly bad at [maths], so I was moved to a group that did commercial maths for O-level instead of straight maths ... that was for people who struggled with the subject ... I got a really bad grade ... one of my lowest grades ... a C or even a D.

The absolute "correctness" or otherwise of answers in mathematics can also leave learners open to the immediate perception of failure in a way that many other subjects do not. Failure may be experienced when making a mistake, not knowing what to do, or seeing others as quicker, more confident, providers of answers. Jackie says:

I remember very little ... I just remember consistently getting it wrong and not knowing why I was getting it wrong.

Even if strategies such as students being encouraged to ask questions, or for help, feature in a more supportive classroom setting, the learner may experience explanations that do not make sense. Jackie remembered experiencing:

...the teacher using words to tell me why I was getting it wrong, but those words not resonating with me and how I learn or how I process information. So, I was feeling double bad about not understanding what they were saying as well as getting the maths wrong.

Experiences of learning mathematics may also involve incomprehensible artefacts:

I remember having a slide rule ... I was terrified of that slide rule. I never ever understood how that worked.

These reported episodes undermined Jackie's sense of competence in mathematics, and her sense of competence in learning mathematics.

Relatedness thwarting. Mathematics may be experienced as isolating, irrelevant, or a source of social shaming, all of which thwart any feelings of relatedness within the learning community. Being asked to display their work publicly seems to be a common feature of adult learners recalled experiences and is often one which evokes intense fear. Many also talk of believing that they are isolated, alone in struggling or being left behind. Jackie remembers feeling comfortable and valued in English lessons, but not in mathematics lessons, perceiving that no-one ever took time with her individually. She was publicly told that she was wrong and felt too embarrassed to ask for what she wanted: an idea of why mathematics matters.

Jackie's account mentions many powerful feelings-shame, embarrassment, anxiety, feeling stupid, hating mathematics, and panic. The consequence of her 
difficult experiences with mathematics was that she perceived it as a threat and attempted to shut it out of her life. However, her negative feelings still emerge in the present:

... just walking over here today, as lovely as you are and very approachable,

I was quite anxious because it was to do with maths.

For many learners, like Jackie, experience of being in mathematics class in school, and having their basic needs for autonomy, competence and relatedness thwarted, has profound consequences in later life.

\section{Need-Supportive Environments for Teaching and Learning}

Social environments, including learning environments, can support the satisfaction of basic needs and lead to positive functioning and development, or thwart the satisfaction of these needs thereby harming functioning and stifling development. Or they may fall between the two, supporting some basic needs, whilst thwarting, or ignoring, others.

The SDT literature tends to focus on autonomy support, rather than dealing with the three basic needs separately. Autonomy is seen as fundamental in enabling individuals to be aware of their needs and their right to choose ways to meet them. Whilst needs can be identified separately, actions that support any one need, and in particular autonomy, are likely to impact on the satisfaction of others.

An autonomy-supportive teacher would, for instance, display a sincere interest in the way students dealt with an exercise and ask them whether they need any additional help. In such a situation, students probably feel they have a say in how to proceed (autonomy satisfaction), are perhaps more likely to feel more confident to improve their skills (competence satisfaction) and feel understood by their teacher (relatedness satisfaction) (Haerens et al., 2015: p. 27). Ryan and Deci (2018) consider autonomy support to involve: enabling, actively encouraging, and valuing meaningful choices; identifying, developing, and supporting a person's interests; valuing their thoughts and feelings; encouraging self-regulation; and taking on their frame of reference.

Choice of tasks is seen as autonomy supportive. Stroet et al. (2013) consider making available tasks that are interesting or important to students, and which also foster the idea of the value of mathematics, supports the development of autonomy in learners. They also see teachers showing respect to students, allowing criticism, and using informational language as further elements of autonomysupportive teaching. Teachers who identify, develop, and support learners' interests are also autonomy-supportive according to Haerens et al. (2015), who further suggest autonomy-supportive teaching practices include using inviting language, offering meaningful choices, and creating opportunities for initiative.

Autonomy-supportive teachers show a sincere interest in how individual students deal with tasks and offer additional help when needed. According to Ryan and Deci (2018), they also give students opportunities to talk, listen to students, 
are responsive to students' comments and questions, acknowledge students' experiences and perspectives, make time for students' independent work, acknowledge signs of improvement and mastery, encourage effort, and offer progressenabling suggestions when asked by students who experience being stuck.

However, autonomy is known to be thwarted in many learning situations, particularly when instructors teach by control, attempt to transmit information to passive and uninterested students, ignore student viewpoints or aim to make students think or behave in a prescribed way. Controlling teaching leads to need-frustration (Bonem et al., 2020). Stroet et al. (2013) clarify that teachers who disrespect, control, or intrude on students, give meaningless or uninteresting tasks, and suppress criticism act against their students' need for autonomy. Haerens et al. (2015) suggest that where students experience pressuring tactics such as punishment or shouting, or hear phrases such as "you have to", they are experiencing an autonomy-thwarting environment, which is supported by Cousins et al. (2019a). Such tactics also act against need for relatedness and against the need for competence. In a controlling environment, students rarely have time to work independently on solving problems, or the opportunity to formulate their own answers which Ryan and Deci (2018) see as necessary to develop students' need for competence.

Stroet et al. (2013) and Leon et al. (2017) characterize competence-supporting environments as involving optimal challenge, provisions of structure through clear instructions and goals, guidance in ongoing activities and the giving of feedback which focuses on the task not the outcome or the student. Guidance on ongoing activities requires teachers to monitor work and offer help, support and encouragement when needed. Throughout, the competence-supporting teachers' attention will be on the process and on the giving of constructive informational feedback. Environments that thwart competence are overly challenging, inconsistent or discouraging. In competence-thwarting environments, feedback is in the form of praise or blame and is often focused on the person rather than their actions.

Research into "optimal challenge" shows that, given choice, children select, and rate as most interesting, those tasks which are one step ahead of their current ability level (Danner \& Lonky, 1981; Lee \& Johnston-Wilder, 2013). Choice seems to be significant here in meeting the need for autonomy, but it also hinges on competence. Students may choose less challenging tasks where their need for competence in mathematics has previously been routinely thwarted (Lee, 2016). In offering choice, teachers must steer a careful path between the energizing nature of sufficient perceived challenge and too much challenge which can be fearor anxiety-inducing. Meeting the need for relatedness will also be important as working collaboratively seems to enable any perceived challenge to be met more readily (Johnston-Wilder \& Lee, 2019).

A relatedness-supporting environment is personal and inclusive, and also features the caring support of others (Ryan and Deci, 2018). Stroet et al. (2013) 
recognise that many teachers are not in a situation to fully meet students' needs for relatedness; due to the size of classes and the organization of the learning environment. |However, where teachers express interest in students' lives, and require everyone within the learning environment to treat one another with respect and care, they can generate feelings of belongingness even in large classes. Leon et al. (2017) consider that teachers can foster student relatedness by demonstrating trust, being available, and paying attention to feelings.

\section{Building Mathematical Resilience}

The concepts and attitudes of mathematical resilience are closely aligned with SDT and seem to offer a way to support both young people as they study mathematics and adults such as Jackie. Mathematical resilience is defined as "maintaining self-efficacy in the face of personal or social threat to mathematical wellbeing" (Johnston-Wilder \& Lee, 2019) and was devised as a pragmatic construct to characterize ways of working that would help develop a positive stance of perseverance and self-safeguarding when learners engage with mathematical ideas. Mathematical resilience aligns with the SDT ideas of need-supportive teaching introduced in the previous section (for example, Cousins et al., 2019b), but is based on further elaboration of the concept and experience of how mathematics anxiety can develop. The term "mathematical resilience" enables teachers and students to say, "I am working to develop mathematical resilience, not mathematics anxiety" and therefore act in ways that develop that resilience. Ideas for resilience-focused mathematics teaching have been extensively explored (Lee \& Johnston-Wilder, 2013, 2017; Johnston-Wilder \& Lee, 2019; Mackrell \& Johnston-Wilder, 2020). Mathematical resilience is based on four attributes. Three of these attributes are clearly resonant with the three basic psychological needs of SDT: personal value of mathematics (autonomy), growth mindset (competence), and community (relatedness).

The fourth attribute of mathematical resilience, struggle (recognizing that engaging in struggle is part of learning mathematics and being able to persist and persevere in learning situations that might provoke anxiety (Williams, 2014)), is a necessary part of mathematical resilience due to the nature of mathematics and its learning. This attribute is not as clearly resonant with current SDT thinking but can relate to both autonomy and competence. Many learners have inadvertently learned that to struggle reveals incompetence. Where teachers use quickfix and path-smoothing routes to rapid, superficial "success", glossing over the understanding needed for autonomy and competence (Stigler \& Hiebert, 2009), students learn that their experience of struggle is because they "can't do it", rather than that everyone has to struggle to learn mathematics. A key aspect of learning about the "struggle" needed to learn mathematics, is learning to manage anxiety if it arises.

In developing mathematical resilience, we recognize the importance of facilitating emotion regulation, providing a framework within which learners are 
enabled to elaborate and gain insight into their emotional responses to mathematics, and are empowered to make different choices. This is defined by Roth et al. (2019) as integrated emotion regulation (IER). IER considers that exploring fears can help learners understand them. IER involves receptive awareness of feelings and taking an active interest in emotional experiences and their meaning, including anxiety. In a series of experiments conducted by Roth et al. (2019), participants were told, prior to seeing a frightening movie clip, either to "take an active interest in their feelings" (IER), or "do their best not to show their feelings", or "try to adopt a detached and unemotional attitude". The participants given the IER instruction showed less fear and had better cognitive recall on a second viewing of the clip. Significantly, a very brief intervention was sufficient to prime IER, so participants experienced less negative emotion and greater cognitive ability.

\section{Tools That Can Help Develop Mathematical Resilience}

A key aspect of mathematical resilience is emotional regulation; a learner with mathematical resilience may still experience anxiety when working with mathematics but will have ways to regulate their response so that they can continue to deal calmly with issues as they arise. We have found that learners who have already developed mathematical avoidance and anxiety need expedients that can help them develop their ability to regulate their emotional responses. Here, we explore the effects of three tools which help learners make sense of their emotional experience when engaging with mathematics (Johnston-Wilder et al., 2020). These tools were offered to Jackie to give her specific actions and strategies for responding to difficult aspects of the emotional experiences she faced when thinking about mathematics. Below each tool is illustrated using examples of how Jackie was introduced to the tool.

Hand Model of the Brain. In the first meeting, Sue introduced the hand model of the brain, based on Siegel (2010), to help Jackie reframe her reported sense of being "stupid" at mathematics and enable her to call a pause whenever needed. The pictures in Figure 1 represent this model.

As she showed Jackie how to put her own hand into the two different positions, Sue described how the wrist in the model represents the brain stem, and the thumb the "primitive part of the brain", shared with all animals, represents the "alarm system". The back of the hand represents the cortex, which is shared with most mammals, and the fingernails represent the prefrontal cortex, where complex human thinking, involved in reading, writing, and arithmetic, takes place.

Sue then connected the folded hand (as shown in Figure 1) with Jackie's experience. Jackie had described that on the way to the session she had experienced nervousness but that by telling herself: "Oh it's okay, it'll be fine, Sue seems kind." she'd managed to arrive at the session in a state of challenge rather than threat. Sue suggested that Jackie's cognition had been regulating her alarm response and 

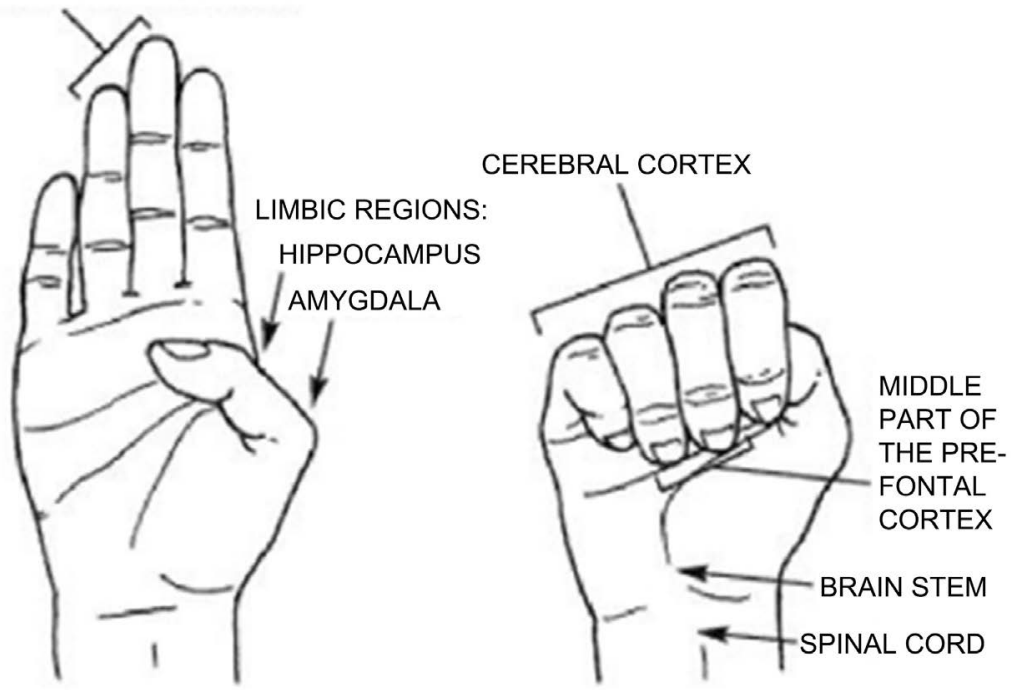

Figure 1. Hand model of the brain (Siegel, 2010) (copyright permission granted).

contrasted this experience with a threat situation in which the alarm system is not regulated, and the brain is effectively "trying to save your life". Sue explained that the system does not distinguish between physical threat and social threat. Anything that results in isolation from the immediate social group can be experienced as a fundamental threat to existence and experiences that result in feelings of shame and humiliation are examples of social threat.

Sue described a common experience in mathematical learning, in which a learner may experience their mind going blank or "feeling stupid" as the cognitive brain function being inhibited, as a temporary state, caused feelings of social threat. In a state of threat, thinking goes offline whilst the brain alters body chemistry to prepare for life-saving fight or flight (Siegel, 2010). The cognitive brain function comes back online only when the perceived threat has been addressed, Jackie was asked to contrast this with the perceived permanent state of being "stupid". Sue said:

... [taking] a moment to recover into connected brain ... managing that initial distress, calming down, and then saying ... what do I need to do to tackle the maths? ... [When] I allow my brain to recover, then all my skills of practical problem-solving kick in ... If you're in panic mode... your brain's trying to save your life from the threat that nobody [else] can see. It's a hidden threat, reacting to social and psychological conditions as well as physical.

The message that the learner is not "stupid" in mathematics, but rather is panicking, thus inhibiting cognitive brain function, enables learners to reframe those times when they felt stupid about mathematics as temporary, rather than permanent, experiences (Williams, 2014).

Relaxation Response. The second tool that Sue introduced was the relaxation 
response (Benson, 2000), which is a technique used in mindfulness meditation. The aim is to bring focus back to the present, taking a "step back" from overwhelming feelings of panic. Sue said:

... If you're a zebra, you run away, and then you go back to chewing again, in the rest-and-digest state, where everything's calm and quiet (what I call the green zone). If you're a diver, then you need to know how to trigger that [response] because if you panic underwater, you use up too much oxygen and then you die, so divers learn explicitly to reduce their heart rate, to reduce the oxygen [use]. If you breathe in for five and out for seven, you are overriding the alarm because you're telling the brain [to activate] the parasympathetic nervous system - the rest-and-digest system.

Growth Zone Model. The third tool Sue used with Jackie gives a pictorial representation of ways in which a learning situation may be experienced.

A diagram like the one in Figure 2 was created by Jackie and Sue working together as Sue explained the idea. Sue said:

The third tool pulls it together ... [Sue draws a circle, Jackie colours it.] Everybody talks about this as the comfort zone, and sometimes you could say: "I'm going to step outside my comfort zone." What we don't talk about very often, and yet it's in the literature, is that there are two spaces outside the comfort zone. [Drawing a ring around the green circle.] There's the growth zone, where you find everything challenging and exciting and slightly unnerving, but you know that you are learning and it's an experience, although it's scary and [you might feel] nervous. ... [Indicating the outside space and drawing an outer ring.] There's the red zone, panic ... threat. When you go into a maths environment, your brain may perceive a threat, so you go straight into red ... And then, with the relaxation response, you learn to get out either back to green or into orange, and then you can tackle any maths problem [in time].

After introducing the three tools, Sue talked to Jackie about a multiplication table and noticed, from Jackie's non-verbal response, that Jackie was feeling

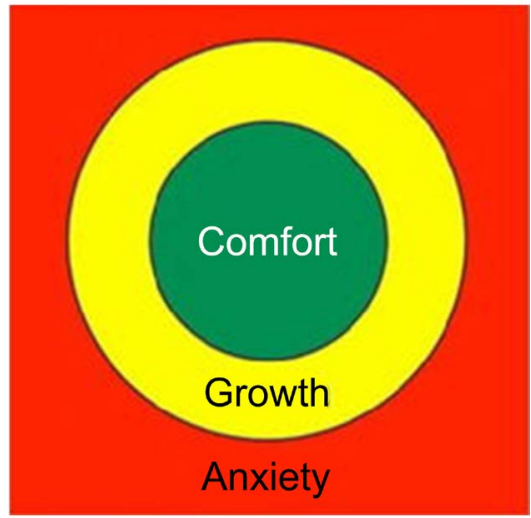

Figure 2. A growth zone diagram (based on Lee and Johnston-Wilder, 2017). 
more anxious. Sue deliberately stopped at this point and encouraged Jackie to use the hand model of the brain to indicate she needed a pause, stressing that she (Sue) would stop until Jackie gave her permission to carry on. Jackie expressed how frightening she found numbers. When Sue asked if it was okay to draw the tiles in a bathroom instead, Jackie indicated that this was alright, because she could visualize the tiles, and Sue used this model to help Jackie create a multiplication table by counting tiles.

\section{The Outcome for Jackie}

Jackie's response to the intervention was very positive. In the first session, after the introduction of the first two tools, Sue asked Jackie how she was feeling. Jackie responded:

I'm feeling much more relaxed and I feel as though I'm almost addressing something that was very unfair many years ago (laughs), because if I'd been open to this, had support with this at that time, my life could have been very different because I could have been embracing maths.

At the beginning of the second session, Jackie commented:

I don't feel embarrassed any more about my struggles with maths, because you made it sound completely ok, and that actually it's not really necessarily my fault. It's the fault of the system ... it's made me feel more positive about it. And other things I struggle with, like the IT and things like that, it's made me feel similarly about that ... I wouldn't say the anxiety has gone, because I still, when I see the little x's ... But the embarrassment has gone. And this is a place of learning, and I want to learn.

She also reported wanting to complete the multiplication table that she had started in the first session:

I felt I wanted to complete that when I got home. And I couldn't actually believe that I was wanting to complete something [in maths] ... who is this person? But I think, because I understood it and I knew I could do it, I wanted to do it. ... those things haven't been in maths for me before.

Jackie also reflected specifically on the three tools. To the hand model, Jackie responded by saying “That's transformational.” During the second session, Jackie said:

[The hand model of the brain] was very powerful, because I felt that it was absolutely ok for me to put my hand up at any point. I wasn't playing a game, where I was thinking I can't possibly put my hand up now and pretending to understand it. I was able to put my hand up, and that made a big difference, because that gave me the confidence to complete this. And I thought, I can connect with something, and that's completely ok, and that's only going to get better. So, I did like that. Because that was about me and how I felt, not how I thought I should feel. 
Jackie recognized the relaxation response from her generic use of mindfulness, but, importantly, would not have thought to apply it to her own issues with mathematics.

I did spend quite a bit of time thinking about [the relaxation response]. Breathing helps me ... You know, you are still alive and if the worst comes to the worst, you can just remove yourself physically from where you are, if you absolutely have to.

Jackie then talked about watching a competition in which someone who was not comfortable with a task took a minute out:

... then he came back, and he said, I'm just going to do what I can. And he asked somebody for some help, and they came and helped him, so he knew where to start. ... I could identify with that, and I thought, yeah, that's what it is all about, really, isn't it? Just saying I need a bit of time out here.

About the growth zone model Jackie said:

it made sense to me as well, because I'd thought quite a lot about the sense of wanting to be in the second zone. Because that's how you develop as a person, not just with maths, but with everything in life. And I think I'm probably quite an anxious person anyway, more than I originally thought. And so, to be in that safe but stretchy zone is good. But then, I can see how, with maths and some things, I tend to go straight from the safe zone to the red zone. There's no in-between. And I think, when I do that, that's when I back off and remove myself.

The intervention clearly changed Jackie's relationship to mathematics. She reported ceasing to feel embarrassed, and, although still feeling anxious, was beginning to view mathematics as a challenge that she could deal with, rather than a threat.

\section{Discussion}

We consider that the impact of the above intervention was due to meeting Jackie's basic psychological needs, through the way Sue engaged in need-supportive teaching, including the use of the three tools, and by the way she worked with Jackie mathematically. Considering these need by need:

Autonomy: Sue prioritized Jackie's choice as to how the intervention proceeded, respecting Jackie's feelings, and valuing her perspective and her needs as a learner.

Competence: The tools described in the previous section supported Jackie's competence as a learner by giving her strategies for emotion management. Awareness that panic can lead to a temporary state of "stupidity" enabled Jackie to reframe beliefs about her ability. Sue consistently asked Jackie to do as much as she could, and when she made mistakes, Sue backtracked to strategies with which Jackie was more confident. 
Relatedness: Sue's responsiveness to Jackie was evidenced throughout the interaction, resulting in feelings of affinity. For example, Jackie described Sue as "lovely" and "very approachable", and described the first session as "interesting", "exciting" and "engaging".

There is also evidence for the relevance of the SDT notions of optimal challenge, mindfulness and integrated emotion regulation. One implication of the SDT notion of optimal challenge, framed in terms of the growth zone model, is that, once learners are confident that they can manage to stay out of the red zone, and are given choice regarding the level of challenge that they choose, they are intrinsically motivated to choose optimal challenge. Jackie gave evidence of being motivated to take on further challenge, wanting to work towards the goal of learning mathematics. She said, "I have started by completing the maths times table ... I also plan to buy an easy Sudoku magazine to help me start enjoying numbers rather than fearing them!"

The relaxation response is connected to mindfulness, in that nurturing awareness of the present moment, either by focusing on breathing or by attending to the environment, enables a shift away from panic. Interestingly, Jackie had not perceived her previous understanding of mindfulness as a strategy to lessen her mathematics anxiety until Sue helped her make that connection.

Jackie was already aware of the value of integrated emotion regulation when the study began.

I'd like to address [maths anxiety] because I think if you address things that you've been fearful about and had anxiety about, it opens up other areas of your life ... you can just live a more fulfilling life, I think.

The mathematical resilience tools specifically enabled Jackie to move toward increasingly integrated emotion regulation in the mathematics learning situation. Instead of blocking out her experience of mathematics, Jackie was able to view and reinterpret it. Her reinterpretation of "feeling stupid" as "panicking" is particularly striking.

The particular understanding of emotional responses to threat, and the concept of the three zones of safety, growth/challenge, and threat, integral to mathematical resilience but not to SDT, appeared to be crucial in providing Jackie with the specific means to reinterpret her experience. We propose the construct "mathematical learning competence" to describe the competence that enables learners to remain in the growth zone, the zone of optimal challenge, in which learning is greatest. Mathematical learning competence specifically involves an awareness of emotions and the tools, support, and strategies to manage those emotions when struggling to engage with mathematics (Mackrell \& Johnston-Wilder, 2020).

\section{Conclusion}

We have shown how SDT is useful as a framework for exploring mathematics 
anxiety, and how it resonates with and supports the outplaying of many of the ideas integral to mathematical resilience. Both SDT and mathematical resilience recognise the importance of a need-supportive environment in promoting learning and preventing anxiety. Mathematical resilience offers tools that help learners to focus on and become aware of their emotions and physiological responses, interpreting these as information which empowers choices other than avoidance, as illustrated in this case study. We recommend that such tools are used to promote a coaching environment where mathematical anxiety can be recognised and overcome. If mathematics anxiety and its destructive power is recognised as a possible outcome of a traditional schooling in mathematics, rather than as a personal characteristic, and ways to deal with it are developed, then that will have benefits for the individual and will prevent them passing that anxiety on to others.

We have much to learn from the lived experience of adults who have been affected by mathematics anxiety; we are particularly struck by the strong aspect of personal shame and embarrassment in accounts such as Jackie's. The change in attitude to mathematics that Jackie reported between the first session and the second is explained not only by the new awareness she gained through experiencing the tools, but also through making sense of a piece of mathematics in a more connected way, so that she experienced competence as a mathematical learner. When she was introduced to the relaxation response, Jackie recognised this as "mindfulness"- but she had not previously thought to apply mindfulness to her own mathematics anxiety.

We suggest that mathematical learning environments are needed that build mathematical resilience and are therefore needs meeting rather than needs thwarting. If mathematics learning environments offer choice and a teacher who listens and is interested in the pupils and promotes a respectful environment, that will begin to meet learners need for autonomy. If the environments also offer optimal challenge and formative feedback which allow the learner to build their skills, then they will also begin to meet the learners' need to feel competence. The need for relatedness may be met through an environment that encourages collaboration and working together to overcome the obstacles that learning mathematics inevitably puts in the way of progress. If these are the features of all environments in which mathematics is learned, then mathematical anxiety will begin to diminish over time. However, until this ideal is reached, mathematics anxiety will still be present in society.

Therefore, we further suggest that interventions to target mathematics anxiety based on the importance of meeting learners' psychological needs (Self-Determination Theory) but including specific responses to facilitate dealing with challenge and threat (mathematical resilience) are particularly important in a world that is increasingly demanding and uncertain and where mathematical understanding and thinking is vital. Interventions that give learners the experience of being liberated from mathematics anxiety may empower these learners to deal 
with other anxieties. Liberation from mathematics anxiety is also key to enabling learners to contribute to the understanding and expertise in STEM subject areas needed to meet current world-wide challenges.

\section{Conflicts of Interest}

The authors declare no conflicts of interest regarding the publication of this paper.

\section{References}

Ashcraft, M., \& Krause, J. (2007). Working Memory, Math Performance, and Math Anxiety. Psychonomic Bulletin \& Review, 14, 243-248. https://doi.org/10.3758/BF03194059

Benson, H. (2000). Relaxation Response. HarperCollins.

Bonem, E., Fedesco, H., \& Zissimopoulos, A. (2020). What You Do Is Less Important than How You Do It: The Effects of Learning Environment on Student Outcomes. Learning Environments Research, 23, 27-44. https://doi.org/10.1007/s10984-019-09289-8

Correia, P., Valle, B, Dazzani, M., \& Infante-Malachias, M. (2010). The Importance of Scientific Literacy in Fostering Education for Sustainability: Theoretical Considerations and Preliminary Findings from a Brazilian Experience. Journal of Cleaner Production, 18, 678-685. https://doi.org/10.1016/j.jclepro.2009.09.011

Cousins, S., Brindley, J., Baker, J., \& Johnston-Wilder, S. (2019a). Stories of Mathematical Resilience: How Some Adult Learners Overcame Affective Barriers. Widening Participation and Lifelong Learning, 21, 46-70. https://doi.org/10.5456/WPLL.21.1.46

Cousins, S., Johnston-Wilder, S., \& Baker, J. (2019b). Mathematics: A Place of Living Kindness and Resilience-Building. Journal of the Canadian Association for Curriculum Studies, 17, 111-126.

Danner, F., \& Lonky, E. (1981). A Cognitive-Developmental Approach to the Effects of Rewards on Intrinsic Motivation. Child Development, 52, 1043-1052. https://doi.org/10.2307/1129110

Deci, E., \& Ryan, R. (2000). The "What" and "Why" of Goal Pursuits: Human Needs and the Self-Determination of Behavior. Psychological Inquiry, 11, 227-268. https://doi.org/10.1207/S15327965PLI1104 01

Durmaz, M., \& Akkus, R. (2016). Mathematics Anxiety, Motivation and the Basic Psychological Needs from the Perspective of Self-Determination Theory. Education and Science, 41, 111-127.

Ellis, J., Fosdick, B., \& Rasmussen, C. (2016). Women 1.5 Times More Likely to Leave STEM Pipeline after Calculus Compared to Men: Lack of Mathematical Confidence a Potential Culprit. PLoS ONE, 11, e0157447.

https://doi.org/10.1371/journal.pone.0157447

EMSI (2018). Focus on the Demand for STEM Jobs \& Skills in Britain. EMSI UK. https://www.economicmodelling.co.uk/wp-content/uploads/2018/12/STEM-Report v WEB.pdf

Finlayson, M. (2014). Addressing Math Anxiety in the Classroom. Improving Schools, 17, 99-115. https://doi.org/10.1177\%2F1365480214521457

Gov.uk (n.d.). Improve Your English, Maths and IT Skills. https://www.gov.uk/improve-english-maths-it-skills 
Haerens, L., Aelterman, N., Vansteenkiste, M., Soenens, B., \& Van Petegem, S. (2015). Do Perceived Autonomy-Supportive and Controlling Teaching Relate to Physical Education Students' Motivational Experiences through Unique Pathways? Distinguishing between the Bright and Dark Side of Motivat Ion. Psychology of Sport and Exercise, 16, 26-36. https://doi.org/10.1016/j.psychsport.2014.08.013

Johnston-Wilder, S., \& Lee, C. (2019). How Can We Address Mathematics Anxiety More Effectively as a Community? 15th International Conference of the Mathematics Education for the Future Project Theory and Practice, Kildare, 4-9 August 2019.

http://oro.open.ac.uk/59217/3/59217.pdf

Johnston-Wilder, S., Brindley, J., \& Dent, P. (2014). A Survey of Mathematics Anxiety and Mathematical Resilience among Existing Apprentices. Gatsby Charitable Foundation.

Johnston-Wilder, S., Kilpatrick Baker, J., McCracken, A., \& Msimanga A. (2020). A Toolkit for Teachers and Learners, Parents, Carers and Support Staff: Improving Mathematical Safeguarding and Building Resilience to Increase Effectiveness of Teaching and Learning Mathematics. Creative Education, 11, 1418-1441.

https://doi.org/10.4236/ce.2020.118104

Lee, C. (2016). Developing Mathematical Resilience: Teachers'Reflections on Working to Develop Mathematical Resilience in Learners. Enigma Mathematics Hub. https://www.m-a.org.uk/resources/downloads/4C-Mel-Muldowney-Developing-Mathe matical-Resilience-Lee.pdf

Lee, C., \& Johnston-Wilder, S. (2013). Learning Mathematics-Letting the Pupils Have Their Say. Educational Studies in Mathematics, 83, 63-180. https://doi.org/10.1007/s10649-012-9445-3

Lee, C., \& Johnston-Wilder, S. (2017). The Construct of Mathematical Resilience. In U. X. Eligio (Ed.), Understanding Emotions in Mathematical Thinking and Learning (pp. 269-291). Academic Press. https://doi.org/10.1016/B978-0-12-802218-4.00010-8

Leon, J., Medina-Garrido, E., \& Núñez, J. L. (2017). Teaching Quality in Math Class: The Development of a Scale and the Analysis of Its Relationship with Engagement and Achievement. Frontiers in Psychology, 8, Article No. 895. https://doi.org/10.3389/fpsyg.2017.00895

Mackrell, K., \& Johnston-Wilder, S. (2020). The Mathematics Resilience Approach to Mathematics Anxiety: Is This Supported by Self-Determination Theory? In R. Marks, (Ed.) Proceedings of the British Society for Research into Learning Mathematics (Vol. 40, pp. 1-6).

https://bsrlm.org.uk/wp-content/uploads/2020/05/BSRLM-CP-40-1-10.pdf

Nardi, E., \& Steward, S. (2003). Is Mathematics T.I.R.E.D? A Profile of Quiet Disaffection in the Secondary Mathematics Classroom. British Educational Research Journal, 29, 345-367. https://doi.org/10.1080/01411920301852

Niemec, C., \& Ryan, R. (2009). Autonomy, Competence, and Relatedness in the Classroom: Applying Self-Determination Theory to Educational Practice. Theory and Research in Education, 7, 133-144. https://doi.org/10.1177\%2F1477878509104318

OECD (Organisation for Economic Co-Operation and Development) (2013). Mathematics Self-Beliefs and Participation in Mathematics-Related Activities. In PISA 2012 Results: Ready to Learn: Students' Engagement, Drive and Self-Beliefs (Vol. 3, pp. 79-104). OECD Publishing. https://www.oecd.org/pisa/keyfindings/PISA2012-Vol3-Chap4.pdf

Roth, G., Vansteenkiste, M., \& Ryan, R. (2019). Integrative Emotion Regulation: Process and Development from a Self-Determination Theory Perspective. Development and Psychopathology, 31, 945-956. https://doi.org/10.1017/S0954579419000403 
Ryan, R., \& Deci, E. (2018). Self-Determination Theory: Basic Psychological Needs in Motivation, Development, and Wellness. Guilford Press.

Siegel, D. (2010). Mindsight: Transform Your Brain with the New Science of Kindness. Oneworld Publications.

Stigler, J., \& Hiebert, J. (2009). The Teaching Gap. New York, NY: The Free Press.

Stroet, K., Opdenakker, M.-C., \& Minnaert, A. (2013). Effects of Need Supportive Teaching on Early Adolescents' Motivation and Engagement: A Review of the Literature. Educational Research Review, 9, 65-87. https://doi.org/10.1016/j.edurev.2012.11.003

Widnall, E., Winstone, L., Mars, B., Haworth, C., \& Kidger, J. (2020). Young People's Mental Health during the COVID-19 Pandemic. NIHR School for Public Health Research.

https://sphr.nihr.ac.uk/wp-content/uploads/2020/08/Young-Peoples-Mental-Health-du ring-the-COVID-19-Pandemic-Report.pdf

Williams, G. (2014). Optimistic Problem-Solving Activity: Enacting Confidence, Persistence, and Perseverance. ZDM, 46, 407-422. https://doi.org/10.1007/s11858-014-0586-y 